BNL-108567-2016-CP

\title{
Laser ion source for isobaric heavy ion collider experiment
}

\author{
T. Kanesue ${ }^{1}$, M. Kumaki ${ }^{2,3}$, S. Ikeda ${ }^{3,4}$, M. Okamura ${ }^{1}$ \\ ${ }^{1}$ Collider Accelerator Department, Brookhaven National Laboratory, \\ Upton, NY 11973 USA \\ ${ }^{2}$ Research Institute for Science and Engineering, Waseda University, \\ Tokyo 169-8555 Japan \\ ${ }^{3}$ Nishina Center for Accelerator-Based Science, RIKEN, Saitama 351-0198 Japan \\ ${ }^{4}$ Interdisciplinary Graduate School of Science and Engineering, Tokyo Institute of \\ Technology, Kanagawa 226-8503 Japan
}

Presented at the $16^{\text {th }}$ International Conference on Ion Sources

New York Marriott Marquis Hotel, New York, NY

August 23 - 28, 2015

To be published in the

Proceedings of the 16th International Conference on Ion Sources:

Review of Scientific Instruments

January 2016

\section{Collider-Accelerator Department Brookhaven National Laboratory}

\section{U.S. Department of Energy Office of Science, Office of Nuclear Physics}

Notice: This manuscript has been authored by employees of Brookhaven Science Associates, LLC under Contract No. DE-SC0012704 with the U.S. Department of Energy. The publisher by accepting the manuscript for publication acknowledges that the United States Government retains a non-exclusive, paid-up, irrevocable, world-wide license to publish or reproduce the published form of this manuscript, or allow others to do so, for United States Government purposes. 


\section{DISCLAIMER}

This report was prepared as an account of work sponsored by an agency of the United States Government. Neither the United States Government nor any agency thereof, nor any of their employees, nor any of their contractors, subcontractors, or their employees, makes any warranty, express or implied, or assumes any legal liability or responsibility for the accuracy, completeness, or any third party's use or the results of such use of any information, apparatus, product, or process disclosed, or represents that its use would not infringe privately owned rights. Reference herein to any specific commercial product, process, or service by trade name, trademark, manufacturer, or otherwise, does not necessarily constitute or imply its endorsement, recommendation, or favoring by the United States Government or any agency thereof or its contractors or subcontractors. The views and opinions of authors expressed herein do not necessarily state or reflect those of the United States Government or any agency thereof. 


\title{
Laser Ion Source for Isobaric Heavy Ion Collider Experiment ${ }^{a)}$
}

\author{
T. Kanesue, ${ }^{1, b)}$ M. Kumaki, ${ }^{2,3}$ S. Ikeda, ${ }^{4,3}$ and M. Okamura ${ }^{1}$ \\ ${ }^{1}$ Collider-Accelerator Department, Brookhaven National Laboratory, Upton, New York 11973, USA \\ ${ }^{2}$ Research Institute for Science and Engineering, Waseda University, Tokyo 169-8555, Japan \\ ${ }^{3}$ Nishina Center for Accelerator-Based Science, RIKEN, Saitama 351-0198, Japan \\ ${ }^{4}$ Interdisciplinary Graduate School of Science and Engineering, Tokyo Institute of Technology, Kanagawa 226-8503, \\ Japan
}

\begin{abstract}
Heavy-ion collider experiment in isobaric system is under investigation at Relativistic Heavy Ion Collider (RHIC). For this experiment, ion source is required to maximize the abundance of the intended isotope. The candidate of the experiment is ${ }^{96} \mathrm{Ru}+{ }^{96} \mathrm{Zr}$. Since the natural abundance of particular isotope is low and composition of isotope from ion source depends on the composites of the target, an isotope enriched material may be needed as a target. We studied the performance of the laser ion source required for the experiment for $\mathrm{Zr}$ ions.
\end{abstract}

\section{INTRODUCTION}

Heavy Ion Collider experiment is under consideration at Relativistic Heavy Ion Collider (RHIC) at Brookhaven National Laboratory. A possible experiment is ${ }^{96} \mathrm{Ru}+{ }^{96} \mathrm{Zr}$. However, the natural abundance of both isotopes of interests is less than several percent, which is shown in Table I. Since the ion yield of the isotope of interest is directly affected by the abundance of a target material, the use of an isotope enriched target may be required though in general it is difficult to obtain such a target or sometimes doesn't exist. At the RHIC accelerator complex, a Laser Ion Source (LIS) combined with an Electron Beam Ion Source (EBIS) is used to provide highly charged heavy ion beams for the RHIC experiments. The LIS generates singly charged ions from a solid state target. The EBIS ionizes the ions further to the charge state required by the following accelerators. The ion source is required to provide ions which have the ratio of charge state to mass over 0.16 , such as $\mathrm{Au}^{32+1}$. Ion beam from the ion source is accelerated by the Radio Frequency Quadrupole (RFQ) accelerator, the interdigital-H type linear accelerator, the booster synchrotron, the AGS synchrotron, before it is injected into the RHIC. ${ }^{2}$ During acceleration, ions are further stripped by stripper foils and fully stripped ions are injected into the RHIC.

LIS also can produce highly charged ions directly by increasing laser power density on a target to increase the plasma temperature. This scheme has been studied from the beginning of the LIS development. ${ }^{3}$ For heavy ion production by LIS, the initial plasma is generated by laser

${ }^{\text {a) }}$ Contributed paper published as part of the Proceedings of the 16th International Conference on Ion Source, New York City, NY, August, 2015.

b) tkanesue@bnl.gov. ablation. A pulsed high power laser light is focused on a solid state target. Electrons in plasma are heated by the intense laser. These hot electrons ionize ions more at the same time the recombination process reduces the ion charge states. The charge state distribution can be controlled by laser power density on the target. To generate plasma dominated with singly charged ions, the laser power density of less than about $10^{9} \mathrm{~W} / \mathrm{cm}^{2}$ is required. ${ }^{4}$ The performance of the LIS for ${ }^{96} \mathrm{Zr}$ ions based on both high-charge state ion production regime and lowcharge state ion production regime were estimated. $\mathrm{Zr}^{16+}$ was assumed in this paper as a targeted charge state from an ion source.

TABLE I. Natural abundances of $\mathrm{Zr}$ and $\mathrm{Ru}$ isotopes.

\begin{tabular}{|l|l|l|l|}
\hline Mass & $\%$ & Mass & $\%$ \\
\hline 90 & 51.45 & 96 & 5.54 \\
\hline 91 & 11.22 & 98 & 1.87 \\
\hline 92 & 17.15 & 99 & 12.76 \\
\hline 94 & 17.38 & 100 & 12.6 \\
\hline 96 & 2.8 & 101 & 17.06 \\
\hline & & 102 & 31.55 \\
\hline & & 104 & 18.62 \\
\hline
\end{tabular}

\section{HIGH CHARGE STATE LASER ION SOURCE}

Base on the previous data, the beam intensity at the RHIC injection is $1.6 \times 10^{9}$ gold ions per bunch in Run-14 and $4.0 \times 10^{9}$ copper ions per bunch in Run-12. ${ }^{2} \mathrm{We}$ assumed that the RHIC can take $5.0 \times 10^{9}$ zirconium ions per bunch at the RHIC injection. Based on $\operatorname{ref}^{2}$, the beam transmission from the booster injection and the RHIC injection could be about $30 \%$. Under the current acceleration scheme, four pulses of ion source pulse will 
be eventually merged into 1 bunch of the RHIC. With these conditions, the ${ }^{96} \mathrm{Zr}$ beam intensity at the booster injection should be more than $4.2 \times 10^{9}$ ions per pulse. Ion beam generated by a LIS contains multiple charge states in a pulse. Based on the experimentally obtained data of silver ions, the maximum abundance of the charge state $\left(\mathrm{Ag}^{15+}\right)$ was about $5 \%{ }^{5}$ Assuming that the abundance of $\mathrm{Zr}^{16+}$ is as same as $\mathrm{Ag}^{15+}$ and the beam transmission between the ion source and the entrance of the booster is $50 \%$, the required total ion yield from LIS could be $2.8 \times 10^{11}$ ions per pulse and $9.9 \times 10^{12}$ ions per pulse with $100 \%$ enriched ${ }^{96} \mathrm{Zr}$ target and natural $\mathrm{Zr}$ target, respectively. The beam pulse width of $10 \sim 40 \mu$ s is required at the booster injection. Given $20 \mu$ s of pulse width and $50 \%$ beam transmission between a LIS and the entrance of the booster the total peak current from a LIS could be about $1270 \mathrm{emA}$ and $35 \mathrm{emA}$ with a $100 \%$ enriched and a natural target, respectively. A direct plasma injection scheme (DPIS) is a way to accelerate such a high current heavy ion beam. With this scheme, the acceleration 60 emA of accelerated beam was demonstrated. ${ }^{6}$ Figure 1 shows the schematic of the DPIS. This indicates that the use of the isotope enriched target could satisfy the requirements. However, a fresh flat surface of the target should be provided at each shot for the stable beam operation in case of the highly charged heavy ion production. This requires the considerable amount of the target, and not feasible with the rare isotope enriched target.

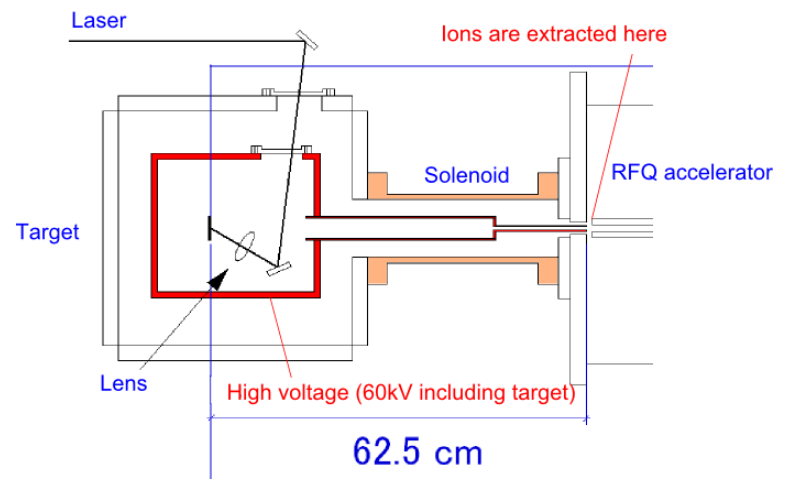

FIG. 1. (Color online). Laser ion source for highly charged, high current heavy ion beam production using Direct Plasma Injection Scheme.

\section{LOW CHARGE STATE LASER ION SOURCE + ELECTRON BEAM ION SOURCE}

The existing RHIC facility uses this method to provide heavy ion beams. Figure 2 shows the schematic of this scheme. At LIS, laser produced plasma dominated by singly charged ions is generated by irradiating a solid state target with moderate laser power density of $\sim 10^{9} \mathrm{~W} / \mathrm{cm}^{2}$, and the plasma expands to the normal direction of the target. A 3m-long solenoid guides the plasma as suppressing the transverse expansion of the plasma to keep the ion beam yield high. The solenoid could enhance the ion beam current at an ion extractor located at the end of the solenoid by a factor of $100 .^{7}$ The beam current at the ion extractor can be controlled by the laser energy and the solenoid field. The extracted ions are transported and injected into an EBIS and trapped by an electron potential, then ions are further ionized by electron beam ion interaction. The maximum ion beam intensity out of the EBIS is determined by a trap capacity, which depends on electron beam and trap length. Based on Run-15 data, the example of the total charge extracted from the EBIS was $9.4 \times 10^{11}$. The charge of $\mathrm{Zr}^{16+}$ ions is $1.9 \times 10^{11}$ assuming that the ratio of $\mathrm{Zr}^{16+}$ when the EBIS is optimized for $\mathrm{Zr}^{16+}$ and the average charge state of the remaining ions are $20 \%$ and $16+$, respectively. The estimated number of $\mathrm{Zr}^{16+}$ ions at RHIC injection could be $1.3 \times 10^{10}$ with a $100 \%$ isotope enriched target, or $3.6 \times 10^{8}$ with a natural target. A $40 \%$ isotope enriched target may satisfy $5.0 \times 10^{9}$.

The performance of a LIS to satisfy the above number was estimated. The minimum number of singly charged ions is $5.9 \times 10^{10}$ with the assumption that As mentioned above, we assumed that the ratio of $\mathrm{Zr}^{16+}$ and the average charge state of the remaining ions are $20 \%$ and 16+, respectively. This doesn't include the losses during injection, ionization, extraction. Assuming that the efficiency between the beam extraction from the LIS and that from the EBIS is $20 \%$, the LIS should supply $2.9 \times$ $10^{11}$ ions per pulse.

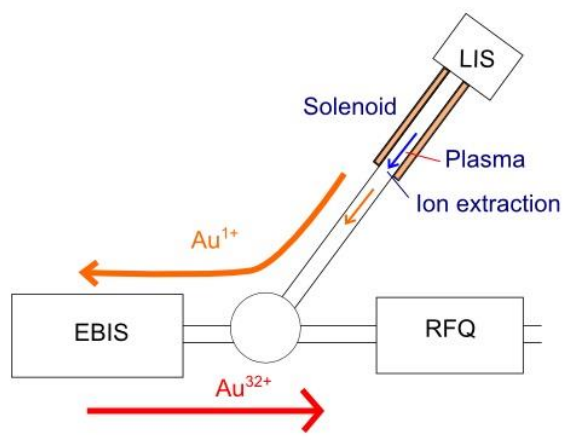

FIG. 2. (Color online). Laser ion source combined with Electron Beam Ion Source (EBIS). EBIS serves as a charge bleeder.

\section{a. SINGLY CHARGED ZIRCONIUM ION PRODUCTION}

We tested $\mathrm{Zr}^{1+}$ ion production on a LIS test bench to verify the available $\mathrm{Zr}$ beam. The experimental setup was similar to that shown in $\operatorname{ref}^{8}$. We used a Nd:YAG laser ( $0.28 \mathrm{~J} / 6 \mathrm{~ns}, \lambda=1064 \mathrm{~nm}$ ). The laser power density on a solid target was $2.6 \times 10^{8} \mathrm{~W} / \mathrm{cm}^{2}$. The charge state distribution of $\mathrm{Zr}$ ions in laser produced plasma was analyzed by an electrostatic ion analyzer, and the total ion current in the plasma was measured by a Faraday Cup (FC). Figure 3 shows the charge state distribution at $1 \mathrm{~m}$ from the target with $1 \mathrm{~cm}^{2}$ aperture, and the measured FC signal. Only $\mathrm{Zr}^{1+}$ was detected and ions of higher charge states were not observed. The ion current density and 
pulse width changes because of the expansion of the laser produced plasma by following relations. ${ }^{3}$

$$
j \propto L^{3}
$$

$\tau \propto L$

where $j$ is current density, $L$ is a distance from the target, and $\tau$ is an ion pulse width. The estimated peak current and pulse width at the full width at half maximum are $5.5 \mu \mathrm{A}$ and $200 \mu \mathrm{s}$. $\mathrm{Zr}$ beam at the ion extractor (3.36 $\mathrm{m}$ far from the target with a $15 \mathrm{~mm}$ extraction aperture). The reason why the peak current is so low compared to that achieved with gold beam $(100 \sim 200 \mu \mathrm{A})$ is that the laser power density is close to the threshold of plasma production and most of laser energy is used to produce neutral gas from the target. To provide the $2.9 \times 10^{11}$ ions for the EBIS, the peak current of $240 \mu \mathrm{A}$ is required. The solenoid should enhance the beam by a factor of 45 , which is within the verified range.

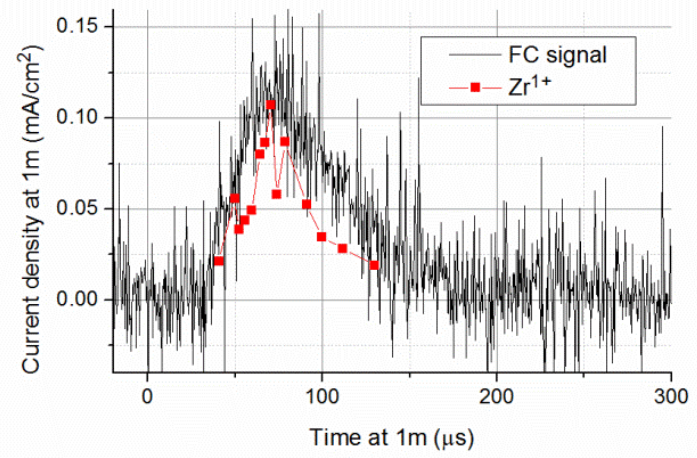

FIG. 3. (Color online). The experimentally analyzed charge state distribution of $\mathrm{Zr}$ ions. The laser power density on a target was $2.6 \times$ $10^{8} \mathrm{~W} / \mathrm{cm}^{2}$. Total ion current in plasma measured by a Faraday Cup is also shown. $\mathrm{Zr}$ ions with charge states more than 2 were not observed.

\section{b. TARGET CONSUMPTION}

The target consumption is an important factor to use an isotope enriched target. The target consumption is roughly estimated based on that of Au target during RHIC run. The amount of Au target used from June to July in 2014 was $2.7806 \mathrm{~g}$, which corresponds to $8.5 \times 10^{21}$ atoms. The number of shots made on the target was about $1.5346 \times 10^{6}$, so the number of atoms escaped from the target per shot was $5.5 \times 10^{14}$. The ions extracted from the LIS was $1.9 \times 10^{11}$, which was estimated based on the typical ion beam shape (peak current $150 \mu \mathrm{A}$, pulse width at full width at half maximum $150 \mu \mathrm{A}$ ). This estimation gives us an idea about the efficiency of target consumption of $3.3 \times 10^{-5}$, where the efficiency is defined as the ratio between the available number of ions from the ion source to the number of atoms escaped from the target. The escaped atoms include neutral atoms or debris. The typical number of laser shots on a target was about $3 \times 10^{5}$ per week with the store length of 7 hours. This number includes the beam for the injector tuning. The target consumption of gold was about $0.54 \mathrm{~g} /$ week. This number could be larger for $\mathrm{Zr}$ since the target consumption tends to be increased for the lighter ions. The target consumption could be reduced by increasing the solenoid field and decreasing the laser power on the target.

\section{CONCLUSION}

The use of a LIS to provide specific isotopes for the RHIC collider experiments was discussed. ${ }^{96} \mathrm{Zr}$ beam was considered as an example. It was found that the LIS in high charge state ion production mode is not feasible because the required beam current is too high with natural target and the target consumption is high for an isotope enriched target. The performance of a LIS in singly charge state ion production mode combined with an EBIS was estimated based on the realistic data obtained during the past RHIC runs. The number of available ${ }^{96} \mathrm{Zr}$ ions at the RHIC injection is estimated to be $1.3 \times 10^{10}$ with a $100 \%$ isotope enriched target, or $3.6 \times 10^{8}$ with a natural target, respectively. In either case, the LIS should supply $2.9 \times$ $10^{11}$ ions per pulse. The experiment with the LIS test bench shows that this can be satisfied. The required target is estimated to be $0.54 \mathrm{~g} /$ week based on the gold consumption data. The actual target consumption should be checked with $\mathrm{Zr}$ target.

\section{ACKKNOWLEDGEMENT}

This work was supported by the U.S. Department of Energy (DOE), and the National Aeronautics and Space Administration (NASA).

${ }^{1}$ J. Alessi, D. Barton, E. Beebe, S. Bellavia, O. Gould, A. Kponou, R. Lambiase, R. Lockey, A. McNerney, M. Mapes, Y. Marneris, M. Okamura, D. Phillips, A. I. Pikin, D. Raparia, J. Ritter, L. Snydstrup, C. Theisen, M. Wilinski, Rev. Sci. Instrument. 81, 02 A509 (2010).

${ }^{2}$ C.J. Gardner, K.L. Zeno, J. Alessi, E. Beebe, I. Blackler, M. Blaskiewicz, J.M. Brennan, K.A. Brown, J. Butler, C. Carlson, W. Fischer, D.M. Gassner, D. Goldberg, T. Hayes, H. Huang, P. Ingrassia, J.P. Jamilkowski, N. Kling, J.S. Laster, D. Maffei, M. Mapes, I. Marneris, G. Marr, A. Marusic, D. McCafferty, K. Mernick, M.G. Minty, J. Morris, C. Naylor, S. Nemesure, S. Perez, A. Pikin, D. Raparia, T. Roser, P. Sampson, J. Sandberg, V. Schoefer, F. Severino, T. Shrey, K. Smith, D. Steski, P. Thieberger, J. Tuozzolo, B. van Kuik, A. Zaltsman, W. Zhang, Proceedings of the International Particle Accelerator Conference 2015, Richmond, May 3-8, 2015 (unpublished), pp. 3804.

${ }^{3}$ B. Sharkov, R. Scrivens, IEEE TRANSACTIONS ON PLASMA SCIENCE, VOL. 33, NO. 6, DECEMBER 2005.

${ }^{4}$ K. Kondo, T. Kanesue, J. Tamura, M. Okamura, Rev. Sci. Instrument. 81, 02A511 (2010).

${ }^{5}$ T. Kanesue, K. Ishibashi, M. Okamura, K. Sakakibara, S. Kondrashev, Proceedings of the European Particle Accelerator Conference 2006, Edinburgh, June 26-30, 2006 (unpublished), pp. 1720.

${ }^{6}$ M. Okamura, H. Kashiwagi, K. Sakakibara, J. Takano, T. Hattori, N. Hayashizaki, R. Jameson, K. Yamamoto, Rev. Sci. Instrument. 77, 03B303 (2006).

${ }^{7}$ K. Takahashi, M. Okamura, M. Sekine, E. Cushing, P. Jandovitz, AIP Conf. Proc. 1525, 241 (2013).

${ }^{8}$ M. Kumaki, S. Ikeda, Y. Fuwa, D. Cinquegrani, M. Sekine, N. Munemoto, T. Kanesue, M. Okamura, M. Washio, , Rev. Sci. Instrument. 85, 02B925 (2014). 